\title{
Standardized reactors for the study of medical biofilms: a review of the principles and latest modifications
}

\section{Authors: Inês B. Gomes, Ana Meireles, Ana L. Gonçalves, Darla M. Goeres, Jelmer Sjollema, Lúcia C. Simões \& Manuel Simões}

This is an Accepted Manuscript of an article published in Critical Reviews in Biotechnology on September 2017, available online: http://www.tandfonline.com/10.1080/07388551.2017.1380601.

Gomes I.B., A. Meireles, A.L. Gonçalves, D.M. Goeres, J. Sjollema, L. C. Simões, M. Simões, "Standardized reactors for the study of medical biofilms: a review of the principles and latest modifications," Critical Reviews in Biotechnology (September 2017): 1-14. 


\section{Standardized reactors for the study of medical biofilms: a review of the principles and latest modifications \\ Ines B. Gomes, Ana Meireles, Ana L. Goncalves, Darla M. Goeres, Jelmer Sjollema, Lucia C. Simoes, and Manuel Simoes.}

\author{
KEYWORDS \\ Biofilm devices; Calgary \\ biofilm device; CDC \\ biofilm reactor; drip flow \\ biofilm reactor; medical \\ applications; \\ reproducibility; rotating \\ disk reactor; \\ standardization
}

\begin{abstract}
Biofilms can cause severe problems to human health due to the high tolerance to antimicrobials; consequently, biofilm science and technology constitutes an important research field. Growing a relevant biofilm in the laboratory provides insights into the basic understanding of the biofilm life cycle including responses to antibiotic therapies. Therefore, the selection of an appropriate biofilm reactor is a critical decision, necessary to obtain reproducible and reliable in vitro results. A reactor should be chosen based upon the study goals and a balance between the pros and cons associated with its use and operational conditions that are as similar as possible to the clin-ical setting. However, standardization in biofilm studies is rare. This review will focus on the four reactors (Calgary biofilm device, Center for Disease Control biofilm reactor, drip flow biofilm reactor, and rotating disk reactor) approved by a standard setting organization (ASTM International) for biofilm experiments and how researchers have modified these standardized reactors and associated protocols to improve the study and understanding of medical biofilms.
\end{abstract}

\section{Introduction}

In the environment, bacteria can be found in suspen-sion (planktonic state) or as biofilms (sessile state). Bacterial biofilms are a self-organized community of microorganisms embedded in a matrix of extracellular polymeric substances (EPS). The EPS protect the bac-teria from environmental stresses, by capturing and concentrating nutrients from the environment and binding bacteria to each other and to surfaces [1,2]. Furthermore, it increases bacterial tolerance to anti-microbial agents [3,4] by limiting diffusion of antimicro-bials through the matrix and by the quenching of antimicrobial agents $[5,6]$. Biofilm formation is carried out in different steps (Figure 1): (i) surface conditioning by adsorption of organic and inorganic molecules pre-sent in the bulk liquid; (ii) planktonic bacteria reversibly attach to a surface through a process mediated by a duel between attractive and repelling forces (flagella and chemotaxis have an important role on overcoming repulsive forces between surfaces); (iii) strong

interactions between bacteria and surfaces cause stable attachment; (iv) adhered bacteria start EPS production;(v) biofilms acquire a three-dimensional (3D) structure; and (vi) biofilms reach a mature pseudo-steady state, where dynamic growth and detachment occurs, dispers-ing biofilm cells to neighboring areas [7,8]. These dynamic structures harbor about $99 \%$ of bacteria pre-sent in the environment [9]. Under stress conditions, it is inexorably more advantageous for bacteria to live as a biofilm than in suspension [2,4]. Possible explanations for this advantage include the protection offered by the EPS matrix against environmental stress [5,6]. Another significant advantage of the biofilm mode of growth is the dispersion potential through detachment, which will allow biofilm recolonization [10]. Following the dir-ection of the fluid, detached cells can travel to other regions and promote new biofilm formation on clean areas [11]. The ability of biofilm bacteria to adapt to variable conditions and the higher percentage of per-sistent bacteria usually found in biofilms are also 


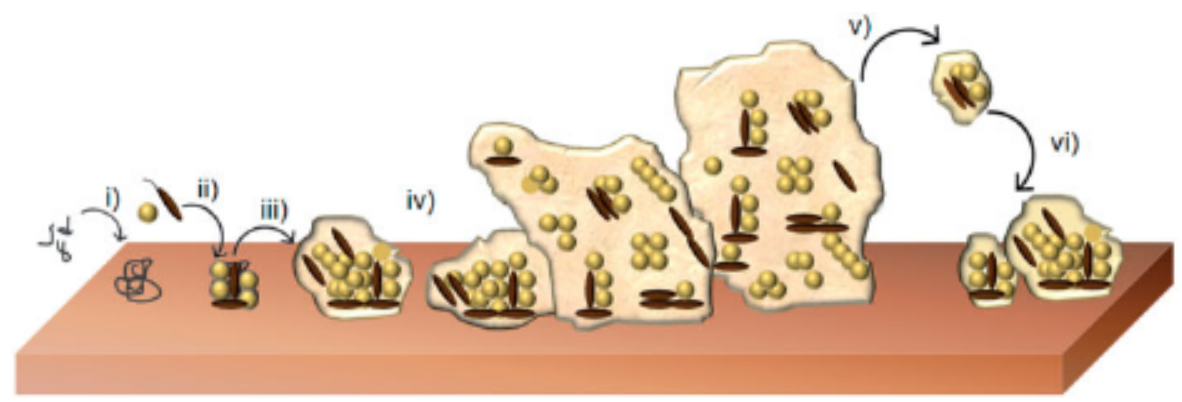

Figure 1. Phases of biofilm formation: (i) adsorption of organic and inorganic molecules present in the bulk liquid to the surface; (ii) transport of planktonic cells from the bulk liquid to the surface and adsorption of cells at the surface; (iii) starting of EPS formation and production of cell-cell signaling molecules; (iv) biofilm maturation, acquisition of a three dimensional structure; (v) biofilm removal by detachment or sloughing; (vi) biofilm recolonization.

important factors that contribute to biofilm tolerance to disinfection [12]. The horizontal gene transfer is also enhanced when microorganisms are in a biofilm state [13]. Also, the metabolic cooperation could be an advantage for bacteria living in biofilms. For example, one species may use a metabolite produced by a neighboring species and, the resistance to antibiotics and host immune responses may also be enhanced in multi-species biofilms [14]. This set of characteristics makes biofilms a concern for human health, mainly when they are formed by pathogens in the human body $[15,16]$.

Biofilms are estimated to be responsible for over $65 \%$ of hospital-acquired infections and $80 \%$ of all microbial infections [8]. Biofilms infect organ tissues, and may colonize indwelling devices $[8,17]$. The presence of microorganisms in specific human tissues is associated with many infections such as, native valve endocarditis (NVE), otitis media, chronic bacterial prostatitis, cystic fibrosis, chronic wounds, and periodontitis $[18,19]$. Candida albicans, coagulase-negative staphylococci, Enterococcus spp., Klebsiella pneumoniae, Pseudomonas aeruginosa, and Staphylococaus aureus are microorganisms commonly associated with biofilm formation on different indwelling devices, such as prosthetic heart valves, artificial voice prosthesis, artificial hip prosthesis, urinary catheters, central venous catheters, and intrauterine devices $[20,21]$. Central venous catheters represent a greater risk of device-related infections, presenting infection rates between 3 and $5 \%$ [22]. For these reasons, it is of utmost importance to study medical biofilms (biofilms formed in medical devices, prosthesis, catheters, or human tissues, usually associated with infections) under conditions simulating as much as possible those encountered in the environment of such devices.

Several studies concerning biofilm formation under different conditions and new strategies to control their development on human tissues and indwelling devices have been published [23-26]. In vivo biofilm studies still remain difficult to perform due to the low control of experiments and to the non-feasibility of some experiments/conditions due to ethical issues $[27,28]$. Therefore, different devices have been used for biofilm formation, trying to mimic the conditions typically found in the human body (e.g. temperature, shear stress, nutrients, relevant clinical microbes, and $\mathrm{pH})$. The use of adequate systems that are able to mimic conditions found in the human body is of great importance to obtain mature biofilms as similar as possible to those which are the cause of chronic human infections. Nevertheless, parameters such as the host immune response, which has an important role on biofilm formation and structure, remain difficult to reproduce. Additionally, the presence of different nutrient conditions should be taken into account when an in vitro experiment is planned. For example, a synthetic infection medium should be prepared according to the human fluids composition during infection conditions [28]. Also, the use of abiotic surfaces for biofilm formation can be a limitation, since implant-related infections only represent a small part of the global infections. In this case, the use of $e x$ vivo samples in in vitro models can be a way to study tissue infections $[27,28]$. Nevertheless, in vitro experiments enable a large number of replicates at a relatively low cost, which allows a better assessment of method variability components. This study provides an updated overview of how researchers are using biofilm reactors in medical biofilm studies, trying to elucidate which are the most appropriate for a specific application. Special attention is given to the panel of standardized reactors (Calgary biofilm device (CBD), Center for Disease Control biofilm reactor (CBR), drip-flow biofilm reactor (DFBR), and rotating disk reactor (RDR)) already applied in this field and to the modifications commonly employed to allow their use in more specific studies. 


\section{Non-standardized devices for the study of medical biofilms}

In situ studies of biofilm-related infections are not ethical or practical. Moreover, the removal of intact biofilms from tissues or indwelling devices and transport to the laboratory for analysis (ex situ) also presents several limitations. Examples of these limitations are the process of biofilm sampling from patients and alteration of the biofilm's natural characteristics [29]. An alternative to ex situ experiments are the in vivo situations using animal models for biofilm studies. However, the control of conditions inside animal models is not an easy and feasible process and ethical problems can develop $[28,30]$. Therefore, the development of in vitro models is an important aspect to consider in the search for new control strategies without any hazard to the host. A wide range of in vitro biofilm models have been developed, each with different attributes. In addition to the standardized reactors, this study will briefly describe other systems that have been used to study biofilms, such as the colony biofilm method, microtiter plates, flow cell reactors, Robbins device and the constant depth film fermenter (CDFF) [28,31].

The simplest in vitro method that has been used is the colony biofilm method, where the biofilm is formed on a semipermeable membrane placed on an agar plate [32,33]. This system is used to study static biofilms (no shear or fluid flow), since colonies formed upon solid growth media have many properties that are similar to biofilms [32]. The colony biofilm method is considered a useful tool for antimicrobial tests [27,32]. Bacterial and yeast colony biofilms were studied in a dynamic system, overcoming the static methodology characterized by nutrients depletion and waste accumulation for which Groisman et al. [34] developed a microfluidic device with chemostat microchambers, which allows microbial growth in a controlled microenvironment. Auxiliary channels were used to connect to the chambers and continuously supply fresh media and remove metabolic waste and avoid cell wash-out. Conventional methods for biofilm formation are low-throughput, require large volumes, and do not allow spatial and temporal control of biofilm community formation. Therefore, Kim et al. [35] developed a poly-dimethylsiloxane (PDMS)-based two layer microfluidic flow cell. This device contains eight separate microchambers to grow biofilms exposed to eight different concentrations of signals through a single diffusive mixing-based concentration gradient generator. Biofilm microchambers are completely isolated due to the existence of pneumatic valves and a cell seeding port. Nevertheless, there is not any approach that is able to mimic real microfluidic dynamics in real biofilms. Microtiter plates have also been extensively used to study biofilms, as they are simple and closed devices that allow bacterial adhesion in wells [36]. Since these devices allow the test of multiple replicates with a low operating volume, they are commonly used for screening large drug libraries [37]. However, these devices work in a batch mode, which means that they are not suitable for simulating the conditions found in the human body. Several authors used microtiter plates to form models of clinically relevant biofilms and to assess their susceptibility to antibiotics and other control strategies, such as bacteriophages [38-40]. These studies presented microtiter plates as effective screening devices, suitable for the study of fundamental research questions, such as the ability of microorganisms to form biofilms in specific conditions and the effectiveness of different compounds on biofilm control and prevention. Benoit et al. [41] presented the Bioflux, a device comprised of microfluidic channels and a distributed pneumatic pump that provides fluid flow to 96 individual biofilms. This device uses a standard well plate format which provides compatibility with plate readers and fine control of the fluid flow.

The continuous culture fermentation apparatus is another example of systems often used to study medically relevant biofilms with increased complexity [27,29]. These reactors try to mimic the environment, industrial and human body processes, enabling a better control of the operational conditions. An example of continuous culture fermentation is the flow cell reactor, which consists of separate containers with removable coupons acting as microbial adhesion surfaces. Pumps are used to provide a continuous flow of the growth medium in the biofilm reactor. This device was also used to study medical biofilms [42,43]. The Robbins device is another flow-through system also used in medical biofilm studies [44]. It consists of a plastic or metal tube into which coupons can be inserted, forming part of the tube wall $[29,45]$. Nickel et al. [45] used a modified Robbins device to simulate the conditions found in catheters. The CDFF is a biofilm system commonly applied to study oral biofilms [46-48]. It consists of a glass vessel with stainless steel (SS) top and bottom plates, containing ports for sampling and medium and gas entrance. Fifteen sampling pans (each one with five plugs) are fitted into a SS plate that is continuously rotating under a scraper blade, ensuring a constant biofilm depth [49]. The parallel-plate flow chamber was developed for studying biofilm formation and their antimicrobial susceptibility [50,51]. Busscher and van der Mei [52] provided a comprehensive review on flow displacement systems for studying microbial adhesion. Microfluidic devices have also been used to study biofilm formation and control. 
These devices allow the precise manipulation of fluids constrained in microscale channels and can be made from a range of materials, such as glass, duroplastic or thermoplastic materials and flexible elastomer PDMS [53,54]. A microfluidic approach for biofilm studies presents some advantages: (i) use of small volumes; (ii) easy to control temperature; (iii) precise gradient generation; (iv) rapid and precise analysis of biofilm; and (v) reduction in the growth variance of in vitro biofilms $[53,55]$. Several works already used microfluidic devices to study medical biofilms [55-57]. Tremblay et al. [56] described a microfluidic method to identify novel factors involved in E. coli biofilm formation and the interaction with the host under shear stress. Subramanian et al. [55] also used a microfluidic device to investigate the treatment of mature $E$ coli biofilms using a combination of low electric fields and small molecule inhibitors (autoinducer 2 analogs) of bacterial quorum-sensing, as an alternative to antibiotics. Shields and Burne [57] used a microfluidic device to study dental biofilms formed by Streptococcus mutans.

\section{Standardized devices for the study of medical biofilms}

In this review, four standardized reactors will be described: CBD; CBR; DFBR; and RDR. The CBR and RDR are standardized reactors that have been used in medical research; however, they were initially designed to develop biofilms growing in engineered systems that tend to mimic the built environment. Although a wide range of distinct biofilm model systems are available, there is not one ideal system that will mimic all the clinical conditions in which biofilms could be found. There are some devices adequate to study low fluid shear stresses, whereas others are more suitable for experiments under higher fluid shear stress. The fluid shear stress varies in the human body and in indwelling devices, meaning that the reactor used to test biofilm formation in a certain part of the human body may not be suitable to simulate other locations. Fluid hydrodynamics is one of the most important factors affecting biofilm structure and behavior. It determines the transport rate of cells to the surface, as well as the transport rate of oxygen and nutrients in the biofilm. Therefore, to mimic medical relevant biofilms it is of utmost importance to use a device able to operate at hydrodynamic conditions close to those commonly found in the human body [58]. Table 1 presents shear stress values that can be observed in different parts of the human body. Knowing such values is important for in vitro biofilm formation under hydrodynamic conditions as similar as possible to those encountered in a real scenario.
Table 1. Shear stress values typically found in the human body and indwelling devices.

\begin{tabular}{lcc}
\hline Human body system/indwelling device & $\begin{array}{c}\text { Shear } \\
\text { stress }(\mathrm{Pa})\end{array}$ & References \\
\hline Arterioles & $1.0-5.0$ & {$[59,60]$} \\
Brachial artery & $0.4-0.5$ & {$[60]$} \\
Brush border cells & $0.1-0.5$ & {$[61]$} \\
Capillary (10 $\mu \mathrm{m}$ of diameter) & $1.0-2.0$ & {$[60,62]$} \\
Carotid artery & $1.1-1.3$ & {$[60]$} \\
Central venous port of the pulmonary & 4.8 & {$[61,63]$} \\
$\quad$ artery catheter & $0.02-2$ & \\
Collecting duct & 0.005 & {$[64]$} \\
Eye & $0.3-0.5$ & {$[65]$} \\
Femoral artery & 0.5 & {$[60]$} \\
Infra-renal aorta & $10-1000$ & {$[60]$} \\
Mouth during food evaluation & 0.05 & {$[66]$} \\
Placenta & 3.6 & {$[67]$} \\
Radial arterial catheter & 0.03 & {$[63]$} \\
Sheath introducer & & {$[63]$} \\
\hline
\end{tabular}

Additionally, selection of an adequate system to study medical biofilms should take into account other engineering aspects. For example, growing a biofilm close to the air/liquid interface is very important for many clinical biofilms, such as lungs, teeth, wounds. In these cases, the DFBR seems to be the most appropriate choice. In catheter studies, however, a plug flow reactor is the one that best mimics the real conditions.

Four methods have been standardized based upon biofilm reactors that grow biofilms under different fluid shear conditions: CBD, CBR, DFBR, and RDR. In a standard method, every step of the protocol is specified, which allows the comparison of data within a single laboratory and among different laboratories. Therefore, a standard method should be: (i) repeatable (independent repeats of the same experiment in the same laboratory produce approximately the same results); (ii) reproducible (independent repeats of the same experiment in different laboratories produce approximately the same results); (iii) rugged (results are unaffected by slight changes in the standard operating procedure); (iv) responsive (the method allows the detection of changes of interest); (v) reasonable (it does not require excessive amounts of time, supplies or highly specialized training); and (vi) relevant (the laboratory outcomes are in agreement with the field outcomes). The main challenge in standardization is to find a proper balance between field relevance and practicality [68]. It is important to note that if a researcher chooses to modify the protocol or reactor set-up, then they must reconfirm that the modified system meets the above described statistical and operational attributes.

A detailed description of the standardized reactors is provided in the following sections. Table 2 presents the main applications, advantages and limitations of each reactor used in the development of the standard 
Table 2. Main applications of standard biofilm reactors and respective advantages and limitations.

\begin{tabular}{|c|c|c|c|c|}
\hline Reactor & Main applications & Advantages & Limitations & Standard method \\
\hline $\begin{array}{l}\text { Calgary biofilm device } \\
\text { (CBD) }\end{array}$ & $\begin{array}{l}\text { Screening of antimicrobial } \\
\text { agents and concentrations } \\
\text { for biofilm control }\end{array}$ & $\begin{array}{l}\text { Requires small space } \\
\text { High-throughput analysis } \\
\text { Easy to control the environ- } \\
\text { mental conditions }\end{array}$ & $\begin{array}{l}\text { Limited to single substrate } \\
\text { materials (no coupons) } \\
\text { Operation in batch mode } \\
\text { Unable to study high shear } \\
\text { stress conditions } \\
\text { Reduced volume }\end{array}$ & $\begin{array}{l}\text { ASTM E2799-12 Standard test } \\
\text { method for testing disin- } \\
\text { fectant efficacy against } \\
\text { Pseudomonos aeruginosa } \\
\text { biofilm using the MBEC } \\
\text { assay }\end{array}$ \\
\hline $\begin{array}{l}\text { CC Biofilm Reactor } \\
\text { (CBR) }\end{array}$ & $\begin{array}{l}\text { Biofilm control with new } \\
\text { materials and antimicrobial } \\
\text { agents } \\
\text { Mimicking indwelling devices } \\
\text { (e.g. catheters and implant- } \\
\text { able cardiac devices) } \\
\text { Model of oral and wounds } \\
\text { biofilms }\end{array}$ & $\begin{array}{l}\text { Possibility to study different } \\
\text { materials simultaneously } \\
\text { Easy to control the hydro- } \\
\text { dynamic conditions } \\
\text { Allows the operation in con- } \\
\text { tinuous mode }\end{array}$ & $\begin{array}{l}\text { Biofilm formed on a flat sur- } \\
\text { face } \\
\text { The flow pattem changes in } \\
\text { the boundaries of the cou- } \\
\text { pons } \\
\text { Lack of sampling surface area }\end{array}$ & $\begin{array}{l}\text { ASTM E2562-12 Standard test } \\
\text { method for quantification } \\
\text { of Pseudomonas aeruginosa } \\
\text { biofilm grown with high } \\
\text { shear and continuous flow } \\
\text { using CCC biofilm reactor } \\
\text { ASTM E2871-13 Standard test } \\
\text { method for evaluating dis- } \\
\text { infectant efficacy against } \\
\text { Pseudomonos aeruginosa } \\
\text { biofilm grown in the CDC } \\
\text { biofilm reactor using the } \\
\text { single tube method }\end{array}$ \\
\hline Drip flow reactor (DFBR) & $\begin{array}{l}\text { Antimicrobial action against } \\
\text { biofilms } \\
\text { Model of biofilms present in } \\
\text { oral cavity, catheters and } \\
\text { wounds }\end{array}$ & $\begin{array}{l}\text { Non-invasive analysis of cell } \\
\text { adhesion and biofilm for- } \\
\text { mation } \\
\text { Allows the operation in con- } \\
\text { tinuous mode } \\
\text { Allows the biofilm growth in } \\
\text { air/liquid interface }\end{array}$ & $\begin{array}{l}\text { Limited to low shear stress } \\
\text { applications } \\
\text { Reduced volume and number } \\
\text { of sampling surfaces } \\
\text { Difficult to control the envir- } \\
\text { onmental conditions }\end{array}$ & $\begin{array}{l}\text { ASTM E2647-13 Standard test } \\
\text { method for quantification } \\
\text { of Pseudomonas aeruginosa } \\
\text { biofilm grown using drip } \\
\text { flow biofilm reactor with } \\
\text { low shear and continuous } \\
\text { flow }\end{array}$ \\
\hline $\begin{array}{l}\text { Rotating disk reactor } \\
\text { (RDR) }\end{array}$ & $\begin{array}{l}\text { Effect of operational condi- } \\
\text { tions on biofilm growth } \\
\text { Antimicrobial action against } \\
\text { biofilms } \\
\text { Model of oral biofilms }\end{array}$ & $\begin{array}{l}\text { Possibility to study different } \\
\text { materials simultaneously } \\
\text { Easy to control the oper- } \\
\text { ational conditions } \\
\text { Allows the operation in con- } \\
\text { tinuous mode }\end{array}$ & $\begin{array}{l}\text { Biofilm formed on a flat sur- } \\
\text { face } \\
\text { The flow pattem changes in } \\
\text { the boundaries of the cou- } \\
\text { pons } \\
\text { Ladk of sampling surface area }\end{array}$ & $\begin{array}{l}\text { ASTM E2196-12 Standard test } \\
\text { method for quantification } \\
\text { of a Pseudomonas aengi- } \\
\text { nosa biofilm grown with } \\
\text { shear and continuous flow } \\
\text { using a rotating disk } \\
\text { reactor }\end{array}$ \\
\hline
\end{tabular}

methods, while Tables S.I-SIV (supplemental file) summarize the studies performed using the four standardized reactors for medical biofilm studies.

\section{Calgary biofilm device}

The CBD, also known as minimum biofilm eradication concentration (MBEC) assay system, is a simple device (Figure 2) originally designed as a test for the assessment of antimicrobials efficacy, as described in the standard method ASTM E2799-12 [69,70]. The CBD is commercially available as a two-part in vitro system. The top component is a lid with 96 pegs [70-72] and the baseplate is a reaction vessel with channels where the pegs fit. However, 96-well microplates can also be used as the baseplate for the system [70,71]. When 96-well microplates are used to fit the pegs, the hydrodynamic conditions are controlled through gyrorotary shakers [73]. On the other hand, when baseplate channels are used, these conditions are controlled with a rocking table [73]. In microtiter plates, the working volume is $200 \mu \mathrm{L}$ per well and in the channel baseplate is $22 \mathrm{~mL}$ in total [73]. The CBD generates repeatable biofilms in the same plate, allowing the study of several conditions/compounds in a single assay $[73,74]$. The lid can be easily transferred to a new baseplate, enabling (a)

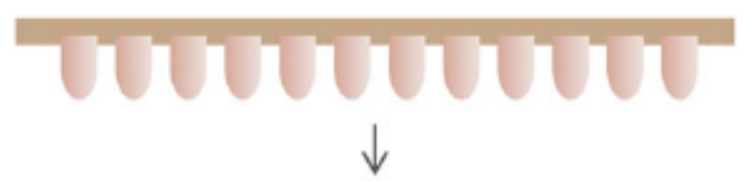

(b)

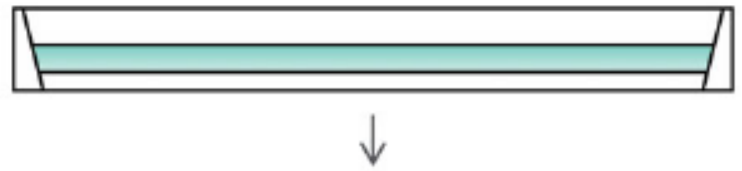

(c)

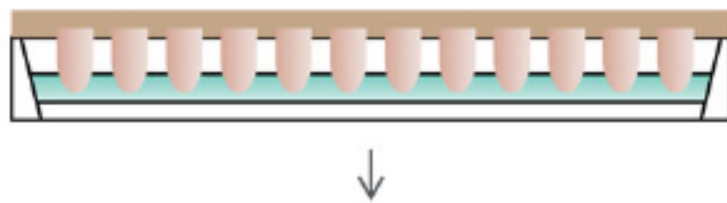

(d)

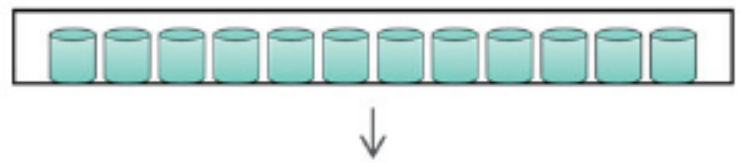

(e)

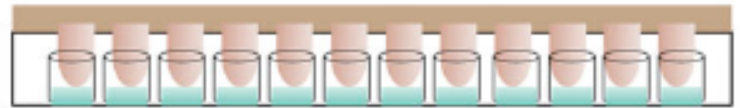

Figure 2. Cross-sectional view of Calgary biofilm device (CBD). (a) Lid with pegs; (b) bottom of the device with channel to insert the medium; (c) lid with pegs inserted in the channel for biofilm formation; (d) cross-sectional view of 96-well microtiter plates; (e) pegs inserted in each well to wash, to scrape or to sample the biofilm. 
an easy replacement of growth media and thus the long-term growth of biofilms [75]. This method typically requires a neutralization step after exposure to antimicrobial agents and the biofilm analysis requires a sonication process for biofilm release into the bulk [76].

The CBD is mostly used to evaluate biofilm eradication using antibiotics or antimicrobials. Ceri et al. [71] used the CBD to determine biofilm antibiotic susceptibility using a method that is similar to the antibiotic susceptibilities test for planktonic populations developed by the Clinical \& Laboratory Standards Institute (CLSI). In that study, Ceri et al. [71] proposed the CBD as a useful technology for the selection of effective antibiotics against microbial biofilms that can also be used for the screening of new effective antibiotic compounds. Rivardo et al. [77] used the CBD to evaluate the efficacy of the V99T14 lipopeptide biosurfactant combined with antibiotics (ampicillin, cefazolin, ciprofloxacin, ceftriaxone, piperacillin, tobramycin, and trimethroprim/sulfamethoxazole) against an uropathogenic $E$ coli strain in both planktonic and biofilm states. The authors observed that combining V99T14 lipopeptide biosurfactant with antibiotics resulted in synergistic action towards biofilm eradication [77]. Molina-Manso et al. [74] studied the susceptibility of staphylococcal biofilms from orthopedic infections against nine antibiotics (rifampicin, vancomycin, ciprofloxacin, trimethoprim/sulfamethoxazole, cloxacillin, clindamycin, tigecycline, daptomycin, and fosfomycin) using the CBD. Saginur et al. [23] studied the control of staphylococcal biofilms from implant-associated infections in CBD using antibiotics in combination. Eleven antimicrobial combinations were found to be active against more than $90 \%$ of MSSA (methicillin-sensitive S. aureus) biofilms, two combinations against MRSA (methicillinresistant S. aureus) biofilms and nine combinations against Staphylococcus epidermidis. Rifampin was the most frequently used antibiotic, especially against $S$. epidermidis. Laverty et al. [78] used the CBD to study the susceptibility of medical device-related pathogens (S. epidermidis, S. aureus, MRSA, P. aeruginosa, and $E$. coli). Gentamicin had the greatest activity against Grampositive bacteria and ciprofloxacin was the most efficient in controlling Gram-negative pathogens. The inhibition of biofilms formed by nosocomial pathogens (S. aureus and $P$. aeruginosa) with esomeprazole was evaluated by Singh et al. [79]. This proton pump inhibitor demonstrated an anti-biofilm effect against the referred pathogens and enhanced the antimicrobial action of vancomycin (against S. aureus) and meropenem (against $P$. aeruginosa).

Other studies were performed to validate the use of the CBD for different microorganisms and applications
(Table S.l). Parahitiyawa et al. [72] used the CBD to develop standardized Candida spp. biofilms. The authors concluded that this is a simple and low-cost system with reduced space requirements, useful for parallel studies of Candida spp. biofilms. Harrison et al. [73] used the CBD in combination with scanning electron microscopy (SEM) and confocal laser scanning microscopy (CLSM) for biofilm organization studies and 3D visualization. The combination of microscopy with biofilm growth in the CBD allowed the structure-function analysis of biofilms. The microorganisms used as models in this work were: E. coli, P. aeruginosa, Pseudomonas chlororaphis, Pseudomonas fluorescens, Burkholderia cenocepacia, S. aureus, and Candida tropicalis. The CBD was also used to develop oral biofilm models derived from natural inoculum from healthy individuals [75].

Hydrodynamic studies have also been performed in the CBD. Salek et al. [24] evaluated the effect of different shear stresses on MRSA biofilm susceptibility to an antibiotic treatment by manipulating the rotational speed $(35,150$, and $300 \mathrm{rpm})$. The increase of shear stress showed an increased susceptibility to a lower amount of vancomycin. The study of shear stress in this device can be conducted using simulation tools, such as computational fluid dynamics (CFD) [24]. There are no reported models or equations that describe the hydrodynamic conditions in this device.

In summary, the CBD is a simple device that requires little space and allows the study of different conditions (compounds and concentrations) in a single assay. The hydrodynamic conditions and temperature are easily controlled. The CBD is an efficient screening tool, since the reactor design allows evaluation of different antimicrobial compounds or concentrations simultaneously [69]. Nevertheless, the CBD has several limitations, namely: (i) the low similarity to indwelling devices, particularly the substrate type (pegs are commonly of polystyrene); (ii) the operation only at low shear stresses; (iii) the low working volume (which can be an advantage when testing expensive compounds); and (iv) the peg shape makes the direct microscopy analysis difficult [71].

\section{$C D C$ control biofilm reactor}

The Center for Disease Control (CDC) biofilm reactor, also known as CBR, was not designed to study medicalrelated biofilms, but it is commonly used to study biofilm formation $[27,80,81]$. Two standard methods (ASTM E2562-12 and ASTM E2871-13) were developed using the CBR for biofilm growth under high shear stress and continuous flow [82-84]. ASTM E2562 describes a protocol for growing biofilms in a CBR and ASTM E2871 


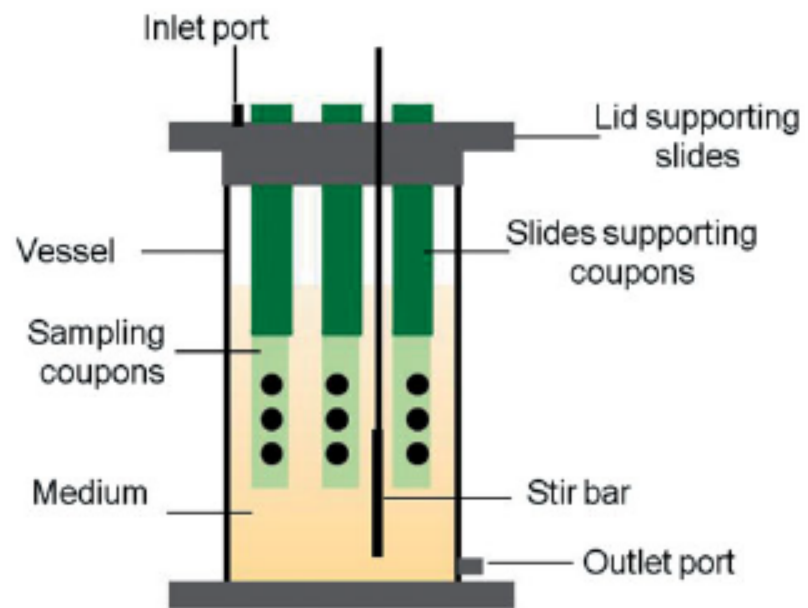

Figure 3. Cross-sectional view of a Center for Disease Control (CDC) biofilm reactor (CBR). The reactor consists in a vessel with eight rods suspended from the reactor lid. Each rod supports three coupons used for biofilm sampling.

describes an efficacy test using the biofilm grown according to the first standard method.

The CBR consists of a 1-L vessel, with eight rods suspended from the reactor lid (Figure 3). Each rod supports three coupons used for biofilm sampling. This reactor can operate in batch or continuous mode, using an auxiliary pump to feed it. Growth medium is fed through a port on the top of the reactor and there is a side-arm effluent port that maintains the volume inside the vessel constant. The lid also supports a magnetic stirrer that incorporates a mixing blade, important to achieve adequate mass transfer and to control the shear stress on the coupon surfaces [85-89]. It is simple to sample the coupons aseptically by removing the rods through the lid [90], which allows measurement of some parameters, such as biofilm thickness, cell density, and viability. It is easy to sterilize the CBR $[90,91]$. Most parts of the reactor can be autoclaved (the exception are coupons, depending on the material tested) before the beginning of the experiments $[85,90,91]$ and the parts that cannot be autoclaved can be sterilized using bleach or ethanol $(70 \%, \mathrm{v} / \mathrm{v})$ [91].

The hydrodynamic conditions of CBR can be estimated using defined equations (Equations (1)-(5)). These equations assume a simplified CBR model consisting of two solid concentric cylinders and describes the shear stress only in the inside surface of the coupon $[68,92]$. This approach was conducted for a clean system (no biofilm on the surface of the coupon, which would affect the boundary conditions) and the fluid properties used were assumed to be the same as for water at room temperature.

$$
\operatorname{Re}=\frac{N \cdot \alpha \cdot R_{\mathrm{o}}^{2} \cdot \rho}{\mu}
$$

$$
\begin{gathered}
R e_{\text {trans. }}=\frac{41.3}{(1-\alpha)^{1.5}} \\
f_{\text {turb. }}=\frac{0.0791}{R e^{0.25}} \\
f_{\text {lam. }}=\frac{16}{R e} \\
\gamma=\frac{f . \rho . N^{2} \cdot R_{\mathrm{i}} \cdot R_{\mathrm{o}}}{2}
\end{gathered}
$$

where $R e$ - Reynolds number; $N$ - rotating speed; $\alpha-$ ratio between inner and outer cylinder radius; $R_{o}$ - outer radius; $\rho$ - fluid density; $\mu$ - dynamic viscosity; $f$ - Fanning friction factor, $\gamma$ - shear stress; $R_{i}-$ inner radius.

Several studies reported the use of the CBR to study biofilm infections on human tissues and in indwelling devices $[86,90,93,94]$. Donlan et al. [94] used the CBR as a model to study nosocomial biofilms of Streptococcus pneumoniae, evaluating EPS formation and cell viability. Williams et al. [26] developed a modified CBR to grow mature $S$. aureus biofilms on the surface of polyetheretherketone (PEEK) membranes for inoculation in an animal model of orthopedic implant biofilm-related infections. In this CBR version, the lid was modified to contain four slots into which guillotine-like holders were inserted; PEEK membranes were placed into the guillotine holders and held in place between two SS plates with an opening. The authors verified that the modifications to the reactor and protocol resulted in a uniform and repeatable mature biofilm on the PEEK membranes' surface [26]. Honraet et al. [85] and Williams and Bloebaum [81] used a CBR to evaluate different strategies to study biofilm formation. Honraet et al. [85] studied three different methods for biomass quantification of Candida spp. biofilms, namely the XTT (2,3-bis-(2-methoxy-4-nitro-5-sulfophenyl)-2H-tetrazolium-5-carboxanilide) cell proliferation assay, fluorescein diacetate (FDA) and SYTO ${ }^{\circledast}$. To evaluate the formation of mature biofilms, Williams and Bloebaum [81] used three different methods of SEM to collect images of $S$. epidermidis ATCC 35984. The CBR was also used in studies aiming to evaluate different treatment strategies. Cai et al. [93] found interesting anti-biofilm activity in diazeniumdiolate-doped poly (lactic-co-glycolic acid)-based nitric oxide releasing coatings that can be applied in indwelling biomedical devices, particularly catheters. Agostinho et al. [86] used a CBR to develop a novel antibacterial envelope for application in implantable cardiac devices. This envelope was impregnated with antibiotics (rifampin and minocycline) that were controllably released from titanium devices, thus avoiding $S$. aureus biofilms formation. Also, Humphreys et al. [87] used a CBR to evaluate the anti-biofilm activity of a formulation 
that combines silver and sodium hexametaphosphate on the treatment of chronic wounds. The action of silver hydrogels was enhanced by the incorporation of polyphosphate. Silver nanoparticles were also tested in $S$. mutans biofilm treatment. The application of these nanoparticles appeared to be advantageous in the prevention and treatment of dental caries. Lora-Tamayo et al. [84] also used the CBR to evaluate the potential of a combination of colistin with doripenem in the control of a multi-drug resistant $P$. aeruginosa biofilm. On the other hand, Garvey et al. [88] used the CBR to form Candida spp. biofilms to obtain a physical sterilization process for application in clinical settings. They found that pulsed UV light was able to decontaminate SS and polyvinyl chloride (PVC) surfaces. The CBR was also used as a dental model. Rudney et al. [90] presented this reactor as a reproducible model for the development of oral microcosm biofilms representative of the oral microbiota. Li et al. [91] used a CBR to hold dentin-composite and hydroxyapatite disks and evaluate the effect of sucrose pulses (mimicking acidogenic meals and snacks) on biofilm behavior.

In the above examples, several modifications were made to the CBR biofilm formation protocol, in order to increase the similarity of the studies to real conditions. The main changes were related to the substrates (coupons), the growth medium used and temperatures applied, which are extremely important factors on biofilm structure and characteristics. Since this reactor was not designed to study medical-related biofilms, these modifications are very important, to operate under process conditions similar to the real environment. However, the rotational speed should be carefully controlled, in order to obtain hydrodynamic conditions similar to those found in real situations.

It is clear that the CBR can be applied in a wide variety of biofilm studies. This reactor allows a simple control of hydrodynamic conditions inside the vessel and the use of coupons allows the simultaneous study of different materials. In addition, the biofilm reaches steady-state growth, making the CBR a good choice for antibiotic efficacy testing. However, it has some limitations, such as the flow pattern changes at the boundaries of the coupons, the use of flat coupons to simulate indwelling devices, which in many cases are cylindrical (e.g. catheters), and also the reduced number of sampling surfaces, compared to those of the MBEC assay [92].

\section{Drip flow biofilm reactor (DFBR)}

The DFBR is a reactor that consists of four completely separate yet parallel channels, each one with an

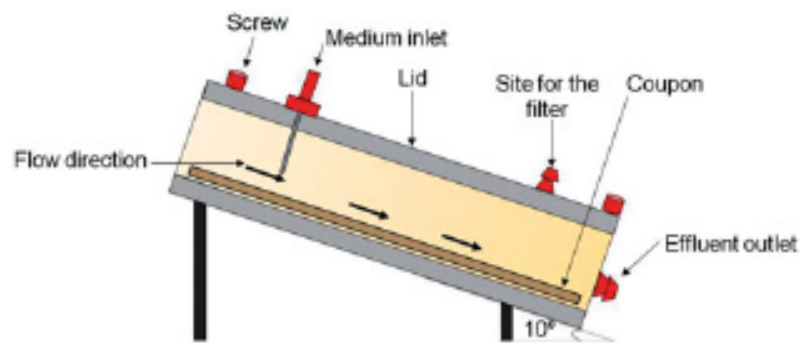

Figure 4. Cross-sectional view of drip flow biofilm reactor (DFBR). DFBR consists of four completely separate yet parallel channels, each one with an individual lid fixed with screws. Each channel contains a coupon that may be made from a variety of materials.

individual lid fixed with screws (Figure 4). The individual lids are important to keep the aseptic conditions during the sampling process. Each channel contains a coupon that may be made of a variety of materials. Stewart et al. [95] tested SS slides, Goeres et al. [96] used glass slides while Ledder et al. [97] and Ledder and McBain [98] formed biofilms on hydroxyapatite-coated slides. Moreover, Curtin and Donlan [99] used all-silicone catheter tubes instead of slides to form biofilms. The medium enters in each chamber through a 21-gauge needle inserted in the lid septum. During operation, the reactor is maintained at an angle of $10^{\circ}$ from the horizontal line and the medium runs down the length of the coupons. To ensure gas exchange, a filter is mounted on the lid $[25,95,100]$. The DFBR is used for studies performed under low shear conditions $[96,100]$ and can be sterilized in an autoclave $[95,97,98]$. This reactor is used in ASTM Method E2647-13 [101] for growing, sampling and analyzing a P. aeruginosa biofilm formed under low shear and continuous flow, trying to mimic the environmental conditions found in indwelling devices and the human body (e.g. catheters, lung with cystic fibrosis and oral biofilms) [101,102].

For DFBR, the Reynolds number (Re) can be calculated according to Equations (6)-(10) [103]. In DFBR there is a falling film flow, therefore for $\operatorname{Re}<20$ a laminar flow with negligible rippling is defined, for $20<\operatorname{Re}$ $<1500$ it is defined a laminar flow with pronounced rippling and if Re $>1500$ the flow is turbulent [103].

$$
\begin{gathered}
v_{\text {max }}=\frac{\rho g \vartheta^{2} \cos \beta}{2 \mu} \\
v=\frac{2}{3} v_{\text {max }} \\
\delta=\sqrt{\frac{3 \mu v}{\rho g \cos \beta}} \\
\operatorname{Re}=\frac{4 \delta v \rho}{\mu} \\
\gamma=\rho g \vartheta \cos \beta
\end{gathered}
$$


where $\rho$ - density of the fluid; $g$ - gravity acceleration; $\vartheta$ - liquid film thickness inside the DFBR; $\beta-80^{\circ}$ (the angle opposite to the inclination - Figure 4); $\mu$ - fluid viscosity; $v_{\max }$ - maximum velocity in DFBR; $\delta$ - fluid film thickness; and $v$-average velocity in DFBR.

Several studies used the DFBR to assess the efficacy of disinfection strategies for biofilm control under low shear stress $[99,102,104]$. Carlson et al. [104] used this reactor to mimic indwelling medical devices and to evaluate the antimicrobial properties of chitosan. Curtin and Donlan [99] studied the control of catheter-associated biofilms with bacteriophages, modifying the DFBR design to allow the connection of catheters segments. Ammons et al. [102] used the DFBR as a biomedical system with $P$. aeruginosa and MRSA isolated from chronic wound debridement samples. The authors evaluated the anti-biofilm efficacy of a lactoferrin/xylitol wound hydrogel used in combination with silver wound dressing. Agostinho et al. [25] analyzed MRSA chronic wound biofilms using a colony/drip flow reactor (C/DFR) model which combined the colony biofilm model and the DFBR. Glass slides were used as support for black polycarbonate membranes where the biofilm was formed. The C/DFR model was a useful tool for performing comparative experiments and testing wound care products and novel antimicrobials. Folsom et al. [105] used the DFBR to evaluate the antimicrobial efficacy of 13 bismuth thiol preparations for bactericidal activity against MRSA and $P$. aeruginosa biofilms isolated from human chronic wounds. Using this reactor, the authors concluded that bismuth thiol compounds are effective against biofilms formed by wound bacteria and can play an important role in the development of topical antiseptics. The literature also contains examples of how the DFBR was used to model oral biofilms $[97,98,106]$. Ledder et al. [97] used a modified DFBR (mDFBR) to evaluate the specificities of selected oral hygiene active compounds in the absence of multiple excipients. This mDFR was also used by Xu et al. [107] and it consists in a Petri plate with slides continuously bathed with medium that drops onto the substratum at a constant rate. Ledder and McBain [98] used the mDFBR to compare different dentrifice formulations in distinct oral microbiotas, where they found that triclosan dentrifice resulted in the largest reductions. Brambilla et al. [106] presented another mDFBR, which allows the placement of customized polytetrafluoroethylene (PTFE) trays at the bottom of flow-cells to maintain the specimen surfaces immersed in the flowing medium. This device was also used to test the performance of five toothpaste formulations.

The DFBR represents situations where biofilms grow at the air/liquid interface under low fluid shear.

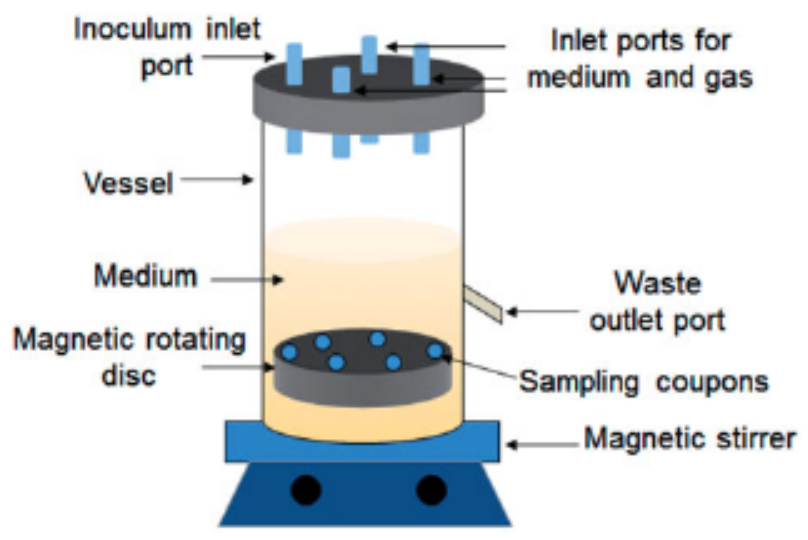

Figure 5. Scheme of a rotating disk reactor (RDR). The RDR consists of a 1-L vessel with a magnetically driven rotor that is placed at the bottom of the vessel. The rotor holds six removable coupons that are the substrate for biofilm formation. The hydrodynamic conditions under which the biofilm is formed are controlled by the magnetically driven rotating disk that continuously mixes the bulk liquid.

Several advantages can be mentioned for this device: it allows a noninvasive sampling, the biofilm can reach a pseudo-steady state (i.e. biofilm amount is almost constant, the amount that are lost to bulk over time is similar to the amount of biofilm formed) and it allows biofilm growth at the air/liquid interface, which is important to mimic some infections (lungs, teeth, and wounds). For these reasons, this reactor was extensively used with different purposes $[95,102,104]$. Nevertheless, the ability to only work with low shear stress and a low number of samples, the difficulty of temperature control, as well as the need for a precise and expensive pump constitute the main disadvantages of this device [96].

\section{Rotating disk reactor}

The RDR was originally used to evaluate the efficacy of biocides against toilet bowl biofilms $[108,109]$. This method was subsequently developed into a standardized biofilm method, ASTM E2196-02 [110]. The RDR consists of a 1-L vessel with an effluent port located at approximately the $250-\mathrm{mL}$ mark. The lid of the reactor has four inlet ports, one for inoculum and three for liquid medium or gas (Figure 5) [111]. There is a magnetically driven rotor, made from PTFE and rubber, which is placed at the bottom of the vessel. The rotor holds six removable coupons that are the substrate for biofilm formation [109,111-113]. The coupons, which are inter-changeable with the $\mathrm{CDC}$ reactor coupons, can be machined from any material and are used to sample the biofilm. The hydrodynamic conditions under which the biofilm is formed are controlled by the magnetically driven rotating disk that continuously mixes the bulk 
liquid [109,111,113]. By adjusting the disk rotation speed, the hydrodynamic conditions in this reactor can be controlled. However, this procedure may not be easy, since it is dependent on the accuracy of the magnetic stirrer. Shear stress on the coupons' surface can be estimated by Equation (11), derived from the Navier-Stokes equations [114].

$$
\gamma=0.729 r \sqrt{\frac{N^{3}}{\delta}}
$$

where $r$ - radius position of coupons; $\delta$ - kinematic viscosity.

The RDR can operate in batch or continuous mode, when connected to a pump. The sterilization process is also very simple, since the entire RDR can be autoclaved [111,113].

The RDR has been used for several biomedical studies. In some studies, system variations were made to enable RDR more appropriate for specific studies $[111,112,115,116]$. Cotter et al. [111] modified the RDR (mRDR) by extending a gas sparger from the lid to below the liquid level that allowed the precise control of the dissolved oxygen (DO) concentration. Winston et al. [115] also reported a mRDR consisting of a 25-mm diameter anodized flat rheometer disk coated with hydroxyapatite. This modification was made to study the rheology of $\mathrm{S}$. mutans biofilms (a dental plaque colonizer). Jin et al. [112] studied different methods to assess cell viability and EPS in biofilms formed by $C$ albicans. The authors modified the RDR to hold 18 polycarbonate coupons. Cell viability was assessed by SYTO ${ }^{\circ}$ and propidium iodide and EPS studies were performed with labeled lectins (Erythrina cristagalli, ECA and Canavalia ensiformis, ConA) that optimized its visualization. Yarwood et al. [117] used a RDR to study quorum-sensing in $S$. aureus biofilms. The authors demonstrated the role of agr expression in biofilm development and showed that its behavior depends on environmental conditions. The detachment of cells expressing agr from biofilms may have important clinical implications, since agr systems contribute to $S$. aureus virulence in biofilm-associated infections, such as endocarditis and osteomyelitis. Other studies used the RDR to study oral biofilms $[115,118]$. For example, Ohsumi et al. [1 18] used this device to evaluate whether residual structure promotes secondary bacterial adhesion after oral disinfection with $70 \%$ isopropyl alcohol using S. mutans as the model microorganism. The authors concluded that disinfected biofilm structures favored secondary bacterial adhesion. Another application for this device is the evaluation of biofilm susceptibility to antibiotics. Garo et al. [109] formed $P$. aeruginosa biofilms under constant rotation speed and evaluated the effect of ciprofloxacin, tobramycin, and two natural compounds (asiatic and corosolic acids) on their treatment. The natural based compounds did not reduce cell viability, but increased the susceptibility of biofilm bacteria to subsequent treatment with tobramycin.

Several advantages and limitations were described for the RDR. One of the advantages of the RDR is that it is possible to grow the biofilm on different materials in parallel, the hydrodynamic conditions may be changed and the reactor operates with a continuous flow of nutrients, allowing for steady-state conditions to be achieved. However, biofilm formation occurs on a flat surface, whose boundary conditions may result in changes to localized flow pattern. This, in addition to the limited number of coupons available, constitutes the main limitations of the system $[119,120]$.

\section{Conclusions}

The use of an appropriate reactor is an important factor to consider in the study of medical biofilms. To obtain reproducible and reliable results, a system should be selected according to the aims of the study and simulating as best as possible the real scenario. The non-standardized most used methods to study biofilms are the 96-well microtiter plates and the flow cell systems. The standardized reactors described in this review are useful for evaluating various medically relevant biofilms and different research goals. A balance between the advantages and limitations should be considered prior to initiating testing. The existence of standard methods and bioreactors is an important aspect to take into account. From the standard described reactors, the CBD is the only apparatus that is not able to operate under continuous flow conditions (as an open system with constant input and output of growth medium) and is ideal as a screening tool for testing new antimicrobial and antifouling compounds. DFBR is suitable to mimic low shear stress situations and the biofilm growth occurs at the air/liquid interface. Therefore, DFBR is suitable to mimic lung infections, teeth biofilms and wounds. On the other hand, CBR and the RDR are more suitable to operate under higher shear stress. The modifications that these reactors have been suffering are important to study new biomaterials. Consequently, with a few modifications (i.e. using different materials or different kinds of coupons) these standard reactors can be used for many studies with medical biofilms, particularly on indwelling devices and human tissues and studying oral biofilms and associated infections. 


\section{Disclosure statement}

The authors declare that there is no conflict of interest.

\section{Funding}

This work was financially supported by:

POCl-01-0145-FEDER-006939 (Laboratory for Process Engineering, Environment, Biotechnology and Energy - UID/ EQU/00511/2013) funded by the European Regional Development Fund (ERDF), through COMPETE2020 Programa Operacional Competitividade e Internacionalização $(\mathrm{POCl})$ and by national funds, through $\mathrm{FCT}$ - Fundação para a Ciencia e a Tecnologia.

NORTE-01-0145-FEDER-000005 - LEPABE-2-ECO-INNOVATION, supported by North Portugal Regional Operational Programme (NORTE 2020), under the Portugal 2020 Partnership Agreement, through the European Regional Development Fund (ERDF).

SFRH/BD/103810/2014, SFRH/BD/52624/2014, SFRH/BD/ $88799 / 2012$ and SFRH/BPD/81982/2011, doctoral and postdoctoral grants attributed by FCT. The work was undertaken as part of the COST Action TD1305.

\section{ORCID}

Inês B. Gomes (D) http://orcid.org/0000-0002-0731-3662

Ana Meireles (D) http://orcid.org/0000-0003-3768-6301

Ana L. Gonçalves (1) http://orcid.org/0000-0002-0691-9646

Darla M. Goeres (D) http://orcid.org/0000-0002-6320-9616

Jelmer Sjollema (D) http://orcid.org/0000-0003-0714-3082

Lúcia C. Simōes (D) http://orcid.org/0000-0002-4893-1985

Manuel Simões (1) http://orcid.org/0000-0002-3355-4398

\section{References}

[1] Costerton JW, Stewart PS, Greenberg EP. Bacterial biofilms: a common cause of persistent infections. Science. 1999;284:1318-1322.

[2] Deva AK, Adams WP Jr, Vickery K. The role of bacterial biofilms in device-associated infection. Plast Reconstruct Surg. 2013;132:1319-1328.

[3] Mah T-FC, OToole GA. Mechanisms of biofilm resistance to antimicrobial agents. Trends Microbiol. 2001;9:34-39.

[4] Simões LC, Simões M. Biofilms in drinking water: problems and solutions. RSC Adv. 2013;3:2520-2533.

[5] Cloete TE. Resistance mechanisms of bacteria to antimicrobial compounds. Int Biodeterior Biodegrad. 2003;51:277-282.

[6] Xue $Z$, Sendamangalam VR, Gruden $\mathrm{CL}$, et al. Multiple roles of extracellular polymeric substances on resistance of biofilm and detached clusters. Environ Sci Technol. 2012;46:13212-13219.

[7] Stowe SD, Richards JJ, Tucker AT, et al. Anti-biofilm compounds derived from marine sponges. Mar Drugs. 2011;9:2010-2035.

[8] Soto SM. Importance of biofilms in urinary tract infections: new therapeutic approaches. Adv Biol. $2014 ; 2014: 13$.
[9] Prakash B, Veeregowda B, Krishnappa G. Biofilms: a survival strategy of bacteria. Curr Sci. 2003;85:1299-1307.

[10] Stewart PS. Mini-review: convection around biofilms. Biofouling. 2012;28:187-198.

[11] Codony F, Morató J, Mas J. Role of discontinuous chlorination on microbial production by drinking water biofilms. Water Res. 2005;39:1896-1906.

[12] Stewart PS. Mechanisms of antibiotic resistance in bacterial biofilms. Int J Med Microbiol. 2002;292: 107-113.

[13] Madsen JS, Burmølle M, Hansen LH, et al. The interconnection between biofilm formation and horizontal gene transfer. FEMS Immunol Med Microbiol. 2012;65:183-195.

[14] Elias S, Banin E. Multi-species biofilms: living with friendly neighbors. FEMS Microbiol Rev. 2012;36: 990-1004.

[15] Fux CA, Wilson S, Stoodley P. Detachment characteristics and oxacillin resistance of Staphyloccocus aureus biofilm emboli in an in vitro catheter infection model. J Bacteriol. 2004;186:4486-4491.

[16] Hall-Stoodley L, Stoodley P. Evolving concepts in biofilm infections. Cell Microbiol. 2009;11:1034-1043.

[17] Romling $U$, Balsalobre C. Biofilm infections, their resilience to therapy and innovative treatment strategies. J Intern Med. 2012;272:541-561.

[18] Donlan RM, Costerton JW. Biofilms: survival mechanisms of clinically relevant microorganisms. Clin Microbiol Rev. 2002;15:167-193.

[19] Bjarnsholt T. The role of bacterial biofilms in chronic infections. APMIS. 2013;121:1-58.

[20] Donlan RM. Biofilm formation: a clinically relevant microbiological process. Clin Infect Dis. 2001;33: 1387-1392.

[21] Vickery $\mathrm{K}, \mathrm{Hu} \mathrm{H}$, Jacombs $\mathrm{AS}$, et al. A review of bacterial biofilms and their role in device-associated infection. Health Infect. 2013;18:61-66.

[22] Berrington A, Gould FK. Use of antibiotic locks to treat colonized central venous catheters. J Antimicrob Chemother. 2001;48:597-603.

[23] Saginur R, StDenis M, Ferris W, et al. Multiple combination bactericidal testing of staphylococcal biofilms from implant-associated infections. Antimicrob Agents Chemother. 2006;50:55-61.

[24] Salek MM, Jones SM, Martinuzzi RJ. Methicillin resistant Staphylococcus aureus biofilm susceptibility in response to increased level of shear stresses and flow agitation. Bioengineering Conference, 2009 IEEE 35th Annual Northeast; 2009 3-5; 2009.

[25] Agostinho AM, Hartman A, Lipp C, et al. An in vitro model for the growth and analysis of chronic wound MRSA biofilms. J Appl Microbiol. 2011;111: 1275-1282.

[26] Williams D, Woodbury K, Haymond B, et al. A modified $C D C$ biofilm reactor to produce mature biofilms on the surface of PEEK membranes for an in vivo animal model application. Curr Microbiol. 2011,62: 1657-1663.

[27] Lebeaux D, Chauhan A, Rendueles O, et al. From in vitro to in vivo models of bacterial biofilm-related infections. Pathogens. 2013;2:288. 
[28] Roberts AEL, Kragh KN, Bjarnsholt T, et al. The limitations of in vitro experimentation in understanding biofilms and chronic infection. J Mol Biol. 2015;427: 3646-3661.

[29] McBain AJ. In vitro biofilm models: an overview. In: Laskin Al, Sariashari S, Gadd G, editors. Advances in applied microbiology, vol. 69. London: Elsevier; 2009.

[30] Kukavica-lbrulj I, Levesque RC. Animal models of chronic lung infection with Pseudomonas aeruginosa: useful tools for cystic fibrosis studies. Lab Anim. 2008;42:389-412.

[31] Coenye T, Nelis HJ. In vitro and in vivo model systems to study microbial biofilm formation. J Microbiol Methods. 2010;83:89-105.

[32] Merritt JH, Kadouri DE, OToole GA. Growing and analyzing static biofilms. Curr Protoc Microbiol. 2005;22:Unit-1B-1.1-1B.1.18.

[33] Ray VA, Morris AR, Visick KL. A semi-quantitative approach to assess biofilm formation using wrinkled colony development. J Vis Exp. 2012,64:e4035.

[34] Groisman A, Lobo $C$, Cho $\mathrm{H}$, et al. A microfluidic chemostat for experiments with bacterial and yeast cells. Nat Methods. 2005;2:685-689.

[35] Kim J, Hegde M, Kim SH, et al. A microfluidic device for high throughput bacterial biofilm studies. Lab Chip. 2012;12:1157-1163.

[36] Sandberg $M$, Maattanen A, Peltonen J, et al. Automating a 96-well microtitre plate model for Staphylococcus aureus biofilms: an approach to screening of natural antimicrobial compounds. Int J Antimicrob Agents. 2008;32:233-240.

[37] Stepanović S, Vuković D, Hola V, et al. Quantification of biofilm in microtiter plates: overview of testing conditions and practical recommendations for assessment of biofilm production by staphylococci. APMIS. 2007;115:891-899.

[38] Macià MD, Rojo-Molinero E, Oliver A. Antimicrobial susceptibility testing in biofilm-growing bacteria. Clin Microbiol Infect. 2014;20:981-990.

[39] Liu H, Zhao Y, Zhao D, et al. Antibacterial and antibiofilm activities of thiazolidione derivatives against clinical staphylococcus strains. Emerg Microbes Infect. 2015;4:e1.

[40] Nouraldin AAM, Baddour MM, Harfoush RAH, et al. Bacteriophage-antibiotic synergism to control planktonic and biofilm producing dinical isolates of Pseudomonas aeruginosa. AJM. 2016;52:99-105.

[41] Benoit MR, Conant CG, lonescu-Zanetti C, et al. New device for high-throughput viability screening of flow biofilms. Appl Environ Microbiol. 2010;76:4136-4142.

[42] Banks MK, Bryers JD. Bacterial species dominance within a binary culture biofilm. Appl Environ Microbiol. 1991;57:1974-1979.

[43] Purevdorj B, Costerton JW, Stoodley P. Influence of hydrodynamics and cell signaling on the structure and behavior of Pseudomonas aeruginosa biofilms. Appl Environ Microbiol. 2002;68:4457-4464.

[44] Kharazmi A, Giwercman B, Høiby N. Robbins device in biofilm research. Methods in enzymology, vol. 310. San Diego: Academic Press; 1999. p. 207-215.

[45] Nickel JC, Ruseska I, Wright JB, et al. Tobramycin resistance of Pseudomonas aeruginosa cells growing as a biofilm on urinary catheter material. Antimicrob Agents Chemother. 1985;27:619-624.

[46] Kinniment SL, Wimpenny JWT, Adams D, et al. Development of a steady-state oral microbial biofilm community using the constant-depth film fermenter. Microbiology. 1996;142:631-638.

[47] Pratten J, Barnett P, Wilson M. Composition and susceptibility to chlorhexidine of multispecies biofilms of oral bacteria. Appl Environ Microbiol. 1998,64: 3515-3519.

[48] Pratten J. Growing oral biofilms in a constant depth film fermentor (CDFF). Curr Protoc Microbiol. 2007,6:1B.5.1-1B.5.18.

[49] Lamfon $H$, Porter SR, McCullough $M$, et al. Susceptibility of Candida albicans biofilms grown in a constant depth film fermentor to chlorhexidine, fluconazole and miconazole: a longitudinal study. J Antimicrob Chemother. 2004;53:383-385.

[50] van der Borden $A$, van der Werf $H$, van der Mei $H C$, et al. Electric current-induced detachment of Staphylococcus epidermidis biofilms from surgical stainless steel. Appl Environ Microbiol. 2004;70: 6871-6874.

[51] Chin MYH, Busscher HJ, Evans R, et al. Early biofilm formation and the effects of antimicrobial agents on orthodontic bonding materials in a parallel plate flow chamber. Eur J Orthod. 2006;28:1-7.

[52] Busscher HJ, van der Mei HC. Microbial adhesion in flow displacement systems. Clin Microbiol Rev. 2006;19:127-141.

[53] Azeredo J, Azevedo NF, Briandet R, et al. Critical review on biofilm methods. Crit Rev Microbiol. 2017;43:313-351.

[54] Franklin MJ, Chang C, Akiyama T, et al. New technologies for studying biofilms. Microbiol Spectr. 2015;3. DOl:10.1128/microbiolspec.MB-0016-2014

[55] Subramanian S, Gerasopoulos K, Guo M, et al. Autoinducer-2 analogs and electric fields - an antibiotic-free bacterial biofilm combination treatment. Biomed Microdev. 2016;18:95.

[56] Tremblay YDN, Vogeleer $P$, Jacques $M$, et al. Highthroughput microfluidic method to study biofilm formation and host-pathogen interactions in pathogenic Escherichia coli. Appl Environ Microbiol. 2015;81:2827-2840.

[57] Shields RC, Burne RA. Growth of Streptococcus mutans in biofilms alters peptide signaling at the sub-population level. Front Microbiol. 2016;7:1075.

[58] Stoodley P, Dodds I, Boyle JD, et al. Influence of hydrodynamics and nutrients on biofilm structure. J Appl Microbiol. 1998;85:19S-28S.

[59] Nagaoka T, Yoshida A. Noninvasive evaluation of wall shear stress on retinal microcirculation in humans. Invest Ophthalmol Vis Sci. 2006;47:1113-1119.

[60] Reneman RS, Hoeks APG. Wall shear stress as measured in vivo: consequences for the design of the arterial system. Med Biol Eng Comput. 2008;46: 499-507.

[61] Guo P, Weinstein AM, Weinbaum S. A hydrodynamic mechanosensory hypothesis for brush border microvilli. Am J Physiol Renal Physiol. 2000;279:F698-F712. 
[62] Wong A, Ye M, Levy A, et al. The blood-brain barrier: an engineering perspective. Front Neuroeng. 2013;6:7.

[63] Frumento RJ, Hirsh AL, Parides MK, et al. Differences in arterial and venous thromboelastography parameters: potential roles of shear stress and oxygen content. J Cardiothorac Vasc Anesth. 2002;16:551-554.

[64] Cai Z, Xin J, Pollock DM, et al. Shear stress-mediated NO production in inner medullary collecting duct cells. Am J Physiol Renal Physiol. 2000;279: F270-F274.

[65] Kang YG, Shin JW, Park SH, et al. Effects of flowinduced shear stress on limbal epithelial stem cell growth and enrichment. PLoS One. 2014,9:e93023.

[66] Mathmann K. Investigation of intraoral mechanical effects on sensory sensations and their contribution to mouthfeel. Munich: Technische Universitat Munchen; 2011.

[67] Beeson JG, Rogerson SJ, Cooke BM, et al. Adhesion of Plasmodium falciparum-infected erythrocytes to hyaluronic acid in placental malaria. Nat Med. 2000;6:86-90.

[68] Goeres DM. Design of model reactor system for evaluating disinfectants against biofilm bacteria. Bozeman, Montana: Montana State University; 2006.

[69] ASTM. Standard test method for testing disinfectant efficacy against Pseudomonas aeruginosa biofilm using the MBEC assay; 2012.

[70] Gu W, Xu D, Sun S. In vitro models to study Candida albicans biofilms. JPDD. 2015;3:301-312.

[71] Ceri $\mathrm{H}$, Olson ME, Stremick $\mathrm{C}$, et al. The Calgary biofilm device: new technology for rapid determination of antibiotic susceptibilities of bacterial biofilms. J Clin Microbiol. 1999;37:1771-1776.

[72] Parahitiyawa NB, Samaranayake YH, Samaranayake $\mathrm{LP}$, et al. Interspecies variation in Candida biofilm formation studied using the Calgary biofilm device. APMIS. 2006;114:298-306.

[73] Harrison JJ, Ceri H, Yerly J, et al. The use of microscopy and three-dimensional visualization to evaluate the structure of microbial biofilms cultivated in the Calgary Biofilm Device. Biol Proced Online. 2006;8:194-215.

[74] Molina-Manso D, del Prado G, Ortiz-Pérez A, et al. In vitro susceptibility to antibiotics of staphylococai in biofilms isolated from orthopaedic infections. Int J Antimicrob Agents. 2013;41:521-523.

[75] Kistler JO, Pesaro M, Wade WG. Development and pyrosequencing analysis of an in-vitro oral biofilm model. BMC Microbiol. 2015;15:24.

[76] Parker AE, Walker DK, Goeres DM, et al. Ruggedness and reproducibility of the MBEC biofilm disinfectant efficacy test. J Microbiol Methods. 2014;102:55-64.

[77] Rivardo F, Martinotti MG, Turner RJ, et al. Synergistic effect of lipopeptide biosurfactant with antibiotics against Escherichia coli CFT073 biofilm. Int J Antimicrob Agents. 2011;37:324-331.

[78] Laverty G, Alkawareek MY, Gilmore BF. The in vitro susceptibility of biofilm forming medical device related pathogens to conventional antibiotics. Dataset Pap Sci. 2014;2014:10.
[79] Singh V, Arora V, Alam MJ, et al. Inhibition of biofilm formation by esomeprazole in Pseudomonas aeruginosa and Staphylococcus aureus. Antimicrob Agents Chemother. 2012;56:4360-4364.

[80] Goeres DM, Loetterle LR, Hamilton MA, et al. Statistical assessment of a laboratory method for growing biofilms. Microbiology (Reading, Engl). 2005; 151:757-762.

[81] Williams D, Bloebaum R. Observing the biofilm matrix of Staphylococcus epidermidis ATCC 35984 grown using the CDC biofilm reactor. Microsc Microanal. 2010;16:143-152.

[82] ASTM. Standard test method for quantification of Pseudomonas aeruginosa biofilm grown with high shear and continuous flow using CDC biofilm reactor; 2012.

[83] ASTM. Standard test method for evaluating disinfectant efficacy against Pseudomonas aeruginosa biofilm grown in the CDC biofilm reactor using the single tube method; 2013.

[84] Lora-Tamayo J, Murillo O, Bergen PJ, et al. Activity of colistin combined with doripenem at dinically relevant concentrations against multidrug-resistant Pseudomonas aeruginosa in an in vitro dynamic biofilm model. J Antimicrob Chemother. 2014,69: 2434-2442.

[85] Honraet K, Goetghebeur E, Nelis HJ. Comparison of three assays for the quantification of Candida biomass in suspension and CDC reactor grown biofilms. J Microbiol Methods. 2005,63:287-295.

[86] Agostinho A, James G, Wazni O, et al. Inhibition of Staphylococcus aureus biofilms by a novel antibacterial envelope for use with implantable cardiac devices. Clin Transl Sci. 2009;2:193-198.

[87] Humphreys G, Lee GL, Percival SL, et al. Combinatorial activities of ionic silver and sodium hexametaphosphate against microorganisms associated with chronic wounds. J Antimicrob Chemother. 2011,66:2556-2561.

[88] Garvey M, Andrade Fernandes JP, Rowan N. Pulsed light for the inactivation of fungal biofilms of clinically important pathogenic Candida species. Yeast. 2015;32:533-540.

[89] Pérez-Díaz MA, Boegli L, James G, et al. Silver nanoparticles with antimicrobial activities against Streptococcus mutans and their cytotoxic effect. Mater Sci Eng C Mater Biol Appl. 2015;55:360-366.

[90] Rudney JD, Chen R, Lenton P, et al. A reproducible oral microcosm biofilm model for testing dental materials. J Appl Microbiol. 2012;113:1540-1553.

[91] Li Y, Carrera C, Chen R, et al. Degradation in the dentin-composite interface subjected to multi-species biofilm challenges. Acta Biomater. 2014;10:375-383.

[92] Gomes IB, Simões M, Simões LC. An overview on the reactors to study drinking water biofilms. Water Res. 2014;62:63-87.

[93] Cai W, Wu J, Xi C, et al. Diazeniumdiolate-doped pol$y$ (lactic-co-glycolic acid)-based nitric oxide releasing films as antibiofilm coatings. Biomaterials. 2012;33: 7933-7944.

[94] Donlan RM, Piede JA, Heyes CD, et al. Model system for growing and quantifying Streptococcus 
pneumoniae biofilms in situ and in real time. Appl Environ Microbiol. 2004;70:4980-4988.

[95] Stewart PS, Rayner J, Roe F, et al. Biofilm penetration and disinfection efficacy of alkaline hypochlorite and chlorosulfamates. J Appl Microbiol. 2001;91:525-532.

[96] Goeres DM, Hamilton MA, Beck NA, et al. A method for growing a biofilm under low shear at the air-liquid interface using the drip flow biofilm reactor. Nat Protoc. 2009;4:783-788.

[97] Ledder RG, Sreenivasan PK, DeVizio W, et al. Evaluation of the specificity and effectiveness of selected oral hygiene actives in salivary biofilm microcosms. J Med Microbiol. 2010;59:1462-1468.

[98] Ledder RG, McBain AJ. An in vitro comparison of dentifrice formulations in three distinct oral microbiotas. Arch Oral Biol. 2012;57:139-147.

[99] Curtin JJ, Donlan RM. Using bacteriophages to reduce formation of catheter-associated biofilms by Staphylococcus epidermidis. Antimicrob Agents Chemother. 2006;50:1268-1275.

[100] Buckingham-Meyer K, Goeres DM, Hamilton MA. Comparative evaluation of biofilm disinfectant efficacy tests. J Microbiol Methods. 2007;70:236-244.

[101] ASTM. Standard test method for quantification of Pseudomonas aeruginosa biofilm grown using drip flow biofilm reactor with low shear and continuous flow; 2013.

[102] Ammons MCB, Ward LS, James GA. Anti-biofilm efficacy of a lactoferrin/xylitol wound hydrogel used in combination with silver wound dressings. Int Wound J. 2011;8:268-273.

[103] Bird RB, Stewart WE, Lightfoot EN. Shell momentum balances and velocity distributions in laminar flow. In: Bird RB, Stewart WE, Lightfoot EN, editors. Transport phenomena. 2nd ed. New York (USA): John Wiley \& Sons, Inc; 2002. p. 43-46.

[104] Carlson RP, Taffs R, Davison WM, et al. Anti-biofilm properties of chitosan-coated surfaces. J Biomater Sci Polym Ed. 2008;19:1035-1046.

[105] Folsom JP, Baker B, Stewart PS. In vitro efficacy of bismuth thiols against biofilms formed by bacteria isolated from human chronic wounds. J Appl Microbiol. 2011;111:989-996.

[106] Brambilla E, lonescu A, Cazzaniga G, et al. The influr ence of antibacterial toothpastes on in vitro Streptococcus mutans biofilm formation: a continuous culture study. Am J Dent. 2014;27:160-166.

[107] Xu KD, Stewart PS, Xia F, et al. Spatial physiological heterogeneity in Pseudomonas aeruginosa biofilm is determined by oxygen availability. Appl Environ Microbiol. 1998;64:4035-4039.

[108] Pitts B, Willse A, McFeters GA, et al. A repeatable laboratory method for testing the efficacy of biocides against toilet bowl biofilms. J Appl Microbiol. 2001,91:110-117.

[109] Garo E, Eldridge GR, Goering MG, et al. Asiatic acid and corosolic acid enhance the susceptibility of Pseudomonas aeruginosa biofilms to tobramycin. Antimicrob Agents Chemother. 2007;51:1813-1817.

[110] ASTM. Standard test method for quantification of a Pseudomonas aenuginosa biofilm grown with shear and continuous flow using a rotating disc reactor; 2012.

[111] Cotter JJ, O'Gara JP, Stewart PS, et al. Characterization of a modified rotating disk reactor for the cultivation of Staphylococcus epidermidis biofilm. J Appl Microbiol. 2010;109:2105-2117.

[112] Jin $Y$, Zhang $T$, Samaranayake $Y H$, et al. The use of new probes and stains for improved assessment of cell viability and extracellular polymeric substances in Candida albicans biofilms. Mycopathologia. 2005; 159:353-360.

[113] Schwartz K, Stephenson R, Hernandez M, et al. The use of drip flow and rotating disk reactors for Staphylococcus aureus biofilm analysis. J Vis Exp. 2010;27:2470.

[114] Pelleïeux S, Bertrand I, Skali-Lami S, et al. Accumulation of MS2, GA, and $Q \beta$ phages on high density polyethylene (HDPE) and drinking water biofilms under flow/non-flow conditions. Water Res. 2012;46:6574-6584

[115] Winston M, Rupp C, Vinogradov AM, et al. Rheology of biofilms. 16th Engineering Mechanics Conference of the American Society of Civil Engineers; Seattle; 2003.

[116] Cotter JJ, O'Gara JP, Mack D, et al. Oxygen-mediated regulation of biofilm development is controlled by the alternative Sigma factor $\sigma(B)$ in Staphylococcus epidermidis. Appl Environ Microbiol. 2009;75:261-264.

[117] Yarwood JM, Bartels DJ, Volper EM, et al. Quorum sensing in Staphylococcus aureus biofilms. J Bacteriol. 2004;186:1838-1850.

[118] Ohsumi T, Takenaka S, Wakamatsu R, et al. Residual structure of Streptococcus mutans biofilm following complete disinfection favors secondary bacterial adhesion and biofilm re-development. PLoS One. 2015; 10:e01 16647.

[119] Murga R, Forster TS, Brown E, et al. Role of biofilms in the survival of Legionella pneumophila in a model potable-water system. Microbiology. 2001;147: 3121-3126.

[120] Möhle RB, Langemann T, Haesner M, et al. Structure and shear strength of microbial biofilms as determined with confocal laser scanning microscopy and fluid dynamic gauging using a novel rotating disc biofilm reactor. Biotechnol Bioeng. 2007;98:747-755. 